\title{
Commentary: Expanding conceptualizations for the study of learning
}

\author{
Rupert Wegerif
}

University of Cambridge, UK

There are always theoretical assumptions involved in research. Theoretical assumptions determine which phenomena are visible and which are invisible and they make different educational goals and pedagogical strategies either thinkable or unthinkable. This collection of articles expands the dialogue about educational research by exploring a range of different ways of conceptually framing education. Each different conceptualisation reveals a different set of objects and relationships and so opens up different ways of thinking about educational goals. For example, Tsafrir Goldberg and Baruch Schwarz bring emotion into the frame in a study which suggests that conventional approaches to education that ignore emotion do so at a cost. Goldberg and Schwarz suggest, with evidence, that by engaging with emotion explicitly we can improve the quality of argumentation and so have a cognitive learning gain. This example illustrates the value of seeing education through a new conceptual frame. Implicit in their account is the potential to understand educational goals in a new way, switching from thinking of education in terms of cognitive development to thinking of it in terms of emotional development. A similar account can be given of each of the articles in this special issue. Each claims to enrich our understanding by foregrounding a different aspect of the complex whole of education thereby enabling us to think in new ways about the nature of education and the goals of education.

Implicit in this first paragraph, and in the introduction to this special issue, is the assumption that expanding the dialogue about education with a range of new conceptualisations is a good thing. But there is an obvious possible challenge to that assumption. Surely the goal of scientific research should not be to proliferate a range of perspectives but to tell us which one is true, or at least more true than the others? This special issue offers us the choice to look at education through the framework of patterns of space and time (Giuseppe Ritella, Beatrice Ligorio and Kai Hakkarainen), social practices (William Penuel, Daniela DiGiacomo, Katie Van Horne and Ben Kirshner), ecology (Crina Damsa and Alfredo Jornet) imagination (Jaakko Hilppö, Antti Rajala, Tania Zittoun, Kristiina Kumpulainen and Lasse Lipponen) as well as the already mentioned focus on emotion (Tsafrir Goldberg and Baruch Schwarz). But in this proliferation of possible perspectives the question must arise which one or which ones should we choose to focus upon and on what basis can we make that choice?

In order to distinguish science from what he called 'pseudo science', Karl Popper used the example of astrology (Popper, 1963). Astrology offers a complex language for describing reality in terms of forces that are said to underlie and control both emotions and events. I do not think that astrology could have survived so long or be so popular if it did not serve some kind of function and that function seems to be helping people feel as if they understand their lives. The example of astrology teaches us that we need to distinguish between the comforting illusion of mastery provided by any analytic framework whatsoever and a more scientific understanding that actually works because it is not simply a social construction but based on correspondence with some sort of underlying reality or transcendental context. 
The social anthropologist Marshall Sahlins pointed out the danger of ontology recapitulating methodology in social science research (1976, p. 89). He made this quip as a criticism of ecological analysis. His point was that first we see everything in terms of interacting organisms and then, after a long complex study, we conclude that everything seems to be interacting organisms. The same could apply to chronotopic analysis. First we assume that everything is patterns of space and time and then we conclude our study by pointing out 'so you see everything turns out to be patterns of space and time'. The point is not, can we look at things this way, but what do we gain if we look at things this way? Given that there are always an infinite number of possible ways of looking at things why should we invest in this one?

Part of the claim made as to the value of chronotopic analysis is as a contrast to assuming the hegemony of a single 'objective' or 'physical' frame of space and time. This is perhaps just a way of acknowledging that different perspectives can be different worlds, not simply points of view within an already given world. This is clear in the example that Ritella et al give of an education project with aboriginal Canadians where local space-time conflicted creatively with scientific space-time.

For Bakhtin, the originator of the concept of chronotope, dialogues were not so much dialogues between people as dialogues between chronotopes. If dialogues are dialogues between chronotopes then there must be a chronotope of chronotopes. Bakthin called this 'Great time': basically the idea of the dialogic space within which different cultures can learn from each other across apparent external distances in space and time. Great time is precisely not the idea of an encompassing context that is monologic, like the idea of an objective overarching context of space and time. But how can we think this dialogic meta-context? Perhaps we cannot think it but we can feel it. In a typically gnomic sentence in his late notes Bakhtin refers indirectly to his concept of great time when he writes: 'the unspoken truth in Dostoevsky (Christ's kiss). The problem of silence.' (Bakhtin, 1986, p. 148). This refers us to a story within a story. In Doestoevsky's the Brothers Karamazov Ivan tells the tale of how Christ, having returned to earth in Seville at the time of the counter-reformation, has been arrested by the Spanish inquisition. The Grand Inquisitor visits his cell and explains his crime. Apparently Christ's mission of freeing humanity was cruel since most humans could not cope with such freedom. Instead they needed the meta-narrative provided by the church. Christ listened in silence to his condemnation and responded only with a single kiss. In this image of Christ's silent kiss we have a radically different way of thinking about education. It suggests a goal beyond the merely cognitive. The ability to understand others' perspectives without becoming lost in them. An understanding that is not verbally articulated but takes the form of love. I suspect that this is a goal for education that follows logically from adopting a chronotopic frame of analysis but I wonder what the authors of the paper think about that.

Perhaps we need a proliferation of different conceptualisations because we find ourselves within education and we cannot have an overview. There is no single master voice or ruling chronotope that we can rely upon. But this does not mean that anything goes and we should treat astrology as if it was science. Goldberg and Schwarz again show a way forward. Not content simply with conceptualising education differently they turn their conceptualisation into an experimental study that tests its value. Their comparison of three methods of education suggest, as a working hypothesis at least, that some ways of educating lead to a more fruitful combination of emotion and cognition than other ways of educating. In my view this is the sort of study that all these different conceptualisation could do and ought to do in order to demonstrate their fruitfulness. It is not enough to say, look this is interesting and seems to make sense - astrologers could say the same. Implicit in putting forward a way of conceptualising education is the claim that this is fruitful for education and if so I think this needs to be explored and demonstrated further with empirical research.

Popper used the example of astrology as a pseudo-science in order to make a contrast with real science. Pseudo-sciences like astrology, psychoanalysis, Marxism and so on were so vague in their claims that they could not be falsified by any evidence. It is hard to see how conceptualising education in terms of space and time or ecology or imagination or social practice could ever be directly falsified. However this does not mean that such conceptualisations are not part of the larger dialogue of educational science. Lakatos argued, against Popper, that the different ways of conceptualising things represented by different scientific 'programmes' did in fact compete and evolve even though they could not be falsified directly. The authors of 
the different ways of conceptualising education in these studies are all claiming that their way of thinking is fruitful for education. Once we acknowledge in all humility that we do not know the truth and can never know it completely then it becomes plausible that a range of different ways of approaching the true might be useful and might in fact, in their own different ways, all be partly true or partly good even while remaining, from our limited point of view, apparently incompatible with each other. In other words the proliferation of many conceptualisations of learning reflects what Bakhtin might call a polyphonic truth where the truth is not to be looked for in any one voice but in the ongoing dialogue.

Normally design-based research seems to assume a given world and just manipulate a few variables within that world. But there is no reason why we cannot extend the design-based research approach to include dialogue between conceptualisations of education. Ultimately we will only know if these different ways of conceptualising education are useful or not if they lead to fruitful consequences. And how do we judge if a consequence is fruitful you ask? I can see why you want clear criteria but that is not how it works. The truth of education is not ultimately a question of theory but a question to be answered by life and by how we live together and construct our future lives together.

\section{References}

Bakhtin, M.M. (1986) Speech Genres and Other Late Essays. Trans. Vern W. McGee. Austin, Tx: University of Texas Press.

Popper, K. (1963) Conjectures and Refutations. Abingdon: Routledge.

Sahlins, M. (1976). Culture and practical reason. University of Chicago Press. 